\title{
Los artefactos de molienda durante los períodos Intermedio Tardío y Tardío en San Pedro de Atacama y Loa Superior ${ }^{1}$
}

Carlos Carrasco G. ${ }^{2}$

\begin{abstract}
RESUMEN
En este trabajo se realiza la caracterización de materiales superficiales de molienda en varios sitios de los períodos Intermedio Tardio y Tardío en la región del Salar de Atacama y Loa Superior, y se intenta un acercamiento a su comportamiento en términos intrasitio. Además, se revisan algunas relaciones funcionales intersitios, así como posibles correlaciones con los productos procesados. Finalmente, en los materiales se registran ciertos atributos para definir categorías, con lo cual es posible advertir situaciones homologables así como diferenciadas en tanto frecuencias tipológicas cualitativas y cuantitativas.
\end{abstract}

Palabras claves: Intermedio Tardío - Tardio - molienda.

\section{ABSTRACT}

This work characterizes surface milling material obtained from sites corresponding to Late Intermediate and Late periods in the Salar de Atacama and Superior Loa regions, and attempts an approach to intra-site terms of behavior. A few functional inter-site relations are also revised, as well as their correlations with processed produce. Finally, the material registers certain category-defining attributes with which it is possible to discern homologous situations from differentiated ones, based on both qualitative and quantitative typological frequencies.

Key Words: Late Intermediate - Late - milling material.

Recibido: febrero 2003. Manuscrito revisado aceptado: enero 2004.

\section{Introducción}

Los artefactos de molienda depositados en sitios habitacionales fueron habituales y recurrentemente utilizados, formando parte de la conducta cotidiana de sus habitantes. La caracterización de estos

1 Investigación financiada por el Proyecto FONDECYT 1000148.

2 Instituto de Investigaciones Arqueológicas y Museo R. P. Gustavo Le Paige s. j., Universidad Católica del Norte, San Pedro de Atacama. Email: c_acg @yahoo.com conjuntos de artefactos en cada sitio permite examinar en términos funcionales el sistema organizativo en que están incluidos y, del mismo modo, la visión de tales conjuntos en distintos sitios permite conocer sistemas conductuales mayores en un ámbito superior de una comunidad y período determinados, es decir, la comparación en términos de semejanzas y diferencias de tales conjuntos nos aproxima a distintas situaciones de uso y estrategias funcionales dentro de contextos sociales, culturales y económicos. En efecto, el registro de tales piezas en sitios tardíos de las cuencas de Atacama y Loa Superior ha permitido observar cómo los asentamientos, al ordenarse en función de tales artefactos, ofrecen asociaciones funcionales, en las que destacan actividades de carácter tanto cotidiano como ceremonial, y cómo ciertos yacimientos se especializan de acuerdo a labores de producción, almacenamiento, procesamiento y consumo de productos tanto vegetales como minerales.

Asimismo, queda de manifiesto el desarrollo de actividades socioculturales y económicas en ámbitos públicos como privados, siendo los materiales de molienda los intermediarios entre los significantes de ciertos productos y quienes los consumen, previo procesamiento ejecutado con tales elementos. De este modo, existe un tránsito o cadena de eventos desde que los productos son obtenidos hasta que son consumidos, en cualquier ámbito privado, público, cotidiano o ceremonial, en donde el último tramo está mediado por los artefactos de molienda. Si bien sólo es posible atribuirles a estos un carácter funcional (moler), tal mediación permite a través de sus frecuencias y variabilidades definir grados de importancia y roles determinados por el uso y la necesidad que se tiene de ellos para el cumplimiento cabal de ciertas metas sociales, ya sean éstas sólo alimenticias (económicas, privadas, cotidianas), consagrativas (socioculturales, públicas, religiosas), así como ambas debidamente integradas. 


\section{Las secuencias culturales}

La cronología propuesta por Tarragó (1989) sobre la base de contextos funerarios, y afianzada por las dataciones TL obtenidas por Berenguer y colaboradores (1986) para los períodos tardíos en la cuenca de Atacama, incluye las fases Yaye, Solor y Catarpe. La primera (950-1200 DC) corresponde a un momento transicional entre las influencias Tiwanaku y comienzos de la reorganización de las poblaciones locales, y al inicio de las relaciones con grupos de tradición YuraHuruquilla. Durante la Fase Solor (1200-1470 DC) se produce el apogeo de los desarrollos regionales manifestándose un control productivo e hidráulico ejercido por una organización jerárquica en torno a un Señorío, estableciéndose relaciones con los desarrollos del Noroeste Argentino (TilcaraYavi), aunque se mantienen los vínculos con las poblaciones altiplánicas. La Fase Catarpe incluye la llegada del Inca a Atacama, postulándose además relaciones con el Noroeste Argentino, debido a la presencia de los tipos cerámicos Inca-Paya y Yavi policromo (Tarragó 1989).

En tanto, para el Loa Superior, Aldunate (1993) definió las fases Turi 1 y Turi 2 a base de investigaciones desarrolladas en el sitio-tipo. La primera se caracteriza por la presencia de un contexto cerámico casi exclusivo Dupont-Aiquina, determinando una etapa inicial del Período Intermedio Tardío, mientras que en la segunda existe una mayor variedad y heterogeneidad cerámica presentándose tipos locales y foráneos, fundamentalmente altiplánicos, puneños e Inca Provinciales, además de cerámica Inca-local.

Sobre este panorama, nuevas investigaciones han elaborado una secuencia para los períodos tardíos que integra los eventos acaecidos contemporáneamente tanto en el Loa Superior como en la cuenca de Atacama, de acuerdo a la alfarería de sitios habitacionales y de colecciones funerarias (Uribe 2002). Esta nueva secuencia incluye cinco fases, con un inicio para el período en la Fase 1, entre los 800-1100 DC, identificada en los sitios Solor y Catarpe, en que se vive una transición entre el Período Medio y el Intermedio Tardío. La Fase 2, que acontece entre 1100-1300 DC, corresponde a una diversificación cultural en San Pedro, así como a una intensificación en las ocupaciones del río Loa y a una mayor interacción areal, detectándose en Yaye, Turi, Caspana,
Chiuchiu, Chacance, Quillagua y Caleta Huelén. En la Fase 3, que se desarrolla entre 1300-1450 DC, se produce la consolidación en las ocupaciones del Loa y San Pedro reflejada en Solor, Catarpe, Turi, Caspana, Quillagua y Caleta Huelén. Hacia la Fase 4, ubicada entre 1450-1500 DC, se produce la avanzada Inca detectada en Solor, Catarpe, Turi y Caspana. Finalmente, durante la Fase 5 (1500-1600 DC), ocurre la consolidación Inca-local y la invasión española, lo que se advierte más nítidamente en Caspana y en el sitio Hostería San Pedro (Uribe 2002).

Estas secuencias se han fundamentado en el Salar de Atacama en el estudio de contextos funerarios (Tarragó 1989) y de sitios habitacionales en el Loa Superior (Aldunate 1993; Uribe et al. 2003; Uribe 2002), y las materialidades registradas en ambos casos permiten distinguir una amplia gama de actividades y relaciones culturales dentro de los ámbitos cotidiano, social y religioso, en donde los artefactos nos acercan a su comprensión. Los materiales de molienda en este caso, tal y como se encuentran en los sitios habitacionales, reflejan directa o indirectamente actividades desarrolladas dentro de aquellos ámbitos, mostrando una organización particular y comparable en los sitios y entre cada uno de estos, pudiéndose determinar sus roles dentro de contextos socioculturales más amplios.

\section{Los materiales y el método}

La información contenida en este estudio se recuperó directamente en terreno de los materiales de superficie de los sitios, aplicando una ficha de registro que recogió información básica para cada pieza visible. La utilización de esta metodología reside en la imposibilidad de hacer una recolección sobre una muestra, y menos sobre el total de estos artefactos, debido a sus considerables dimensiones, peso y falta de espacio para almacenamiento. Sin embargo, aunque en cada asentamiento se realizó una búsqueda y fichaje acucioso con el fin de obtener el mayor número posible de piezas representadas, se supone que el registro fue parcial, ya que en la mayoría de los casos la manufactura de las piezas se realizó sobre las mismas materias primas con las cuales se construyen los muros de los sitios, por lo que resulta muy difícil, y a veces prácticamente imposible, revisar cada una de las piedras de muro derrumbado para verificar si se trata o no de un artefacto, ya que tam- 
bién se han utilizado instrumentos de molienda descartados en la construcción de éstos. ${ }^{3}$

En cuanto a los atributos registrados, y teniendo en cuenta la variabilidad artefactual, se priorizó la identificación de categorías etnográficas (p.e., conanas, manos, morteros, etc.) por sobre las formas específicas de cada pieza (ovoides, circulares, etc.), con el objeto de lograr una caracterización funcional más que morfológica, lo que se obtuvo mediante la consideración de variables tecnológicas como las materias primas, los tipos de desgaste tanto de uso como de formatización de las piezas, la ubicación de las modificaciones y el estado de conservación. Otro interés fue estudiar el comportamiento espacial de estas piezas dentro de los sitios, registrándose el número del recinto donde se ubican, así como su disposición en éstos, considerando si están al interior o exterior de ellos, sobre alguno de sus muros o formando parte de la construcción.

Para efectos operacionales se define molienda como la acción de moler (reducir a polvo), machacar o triturar, con al menos dos elementos, que involucran una parte inmóvil (molinos) y otra móvil (manos) accionada por fuerza humana. Tales elementos se diferencian en varios tipos de acuerdo a los atributos antes señalados.

Como parte inmóvil o molinos se han identificado tacitas, morteros, conanas y metates. Las tacitas corresponden a huecos de distintas profundidades y formas existentes sobre enormes bloques rocosos imposibles de mover; los morteros son piezas cuyo hueco es cónico y/o de planta circular; las conanas son aquellas cuya cavidad en planta es más larga que ancha, en tanto que los metates son piedras planas que presentan huellas de uso, ya sean éstas por pulimento, trituramiento o piqueteado. Las tacitas y morteros reciben en sus cavidades movimientos verticales y/o circulares, mientras que en las conanas y metates la dirección del movimiento es horizontal. Por su parte, las partes móviles se han diferenciado en manos y machacadores, siendo las primeras aquellas piezas cuyas huellas de uso corresponden a pulimento ubicado en cualquiera de sus caras o sobre más de una de ellas,

3 Cornejo (1990) menciona la misma dificultad para el registro de este tipo de materiales en superficie en el Pucara de Turi. mientras que los segundos se han definido a partir de que sus huellas de uso, ya sean determinadas por pulido, piqueteado o trituramiento, se ubican en el sector frontal de uno o ambos extremos distales del ejemplar. Las manos siguen un movimiento horizontal sobre la parte inmóvil a utilizar, en tanto que los machacadores experimentan movimientos verticales y/o circulares.

Otras piezas consideradas, pero que no se identifican directamente como instrumentos de molienda, son los yunques, percutores y pulidores. Los yunques se han definido por presentar huellas de trituramiento en una o dos de sus caras; los percutores exhiben trituramiento o piqueteado en el sector lateral de uno o dos de sus extremos distales; en tanto, los pulidores son pequeños guijarros completamente pulidos que presentan estrías en cualquiera de sus caras.

Una característica recurrente aunque no determinante de los materiales fue el registro de más de una función en una misma pieza. Se llamó, por lo tanto, multifuncionales a aquellas piezas con más de una funcionalidad dentro de un mismo ámbito de operación ya sea como artefacto de molienda (p.e., mano-machacador; mano-metate; conanametate; etc.) o como implemento de talla (p.e., yunque-percutor), haciendo la diferencia entre multifuncional-móvil, para referirnos a aquellas piezas que mezclan huellas de uso como manos tanto en dirección vertical como horizontal (p.e., manos y machacadores), y multifuncional-inmóvil para representar a aquellas que funcionaron como molinos con más de una forma (p.e., conanametate). Por otra parte, a aquellas que combinan funciones como artefactos de molienda y como implementos de talla (p.e., mano-yunque; metateyunque; mano-percutor; etc.) se les llamó polivalentes, sólo como una manera efectiva de diferenciarlas de aquellas piezas que combinan funciones de molienda o de implementos de talla sin cruzarse ambos ámbitos de acción o multifuncionales.

El Gráfico 1 muestra las frecuencias de artefactos en términos genéricos presentes en cada sitio.

\section{Los sitios}

En este estudio se trabajó con 11 sitios: nueve de la región de San Pedro de Atacama y dos del Loa Superior, correspondientes a Guatin, Solor, Vilama 


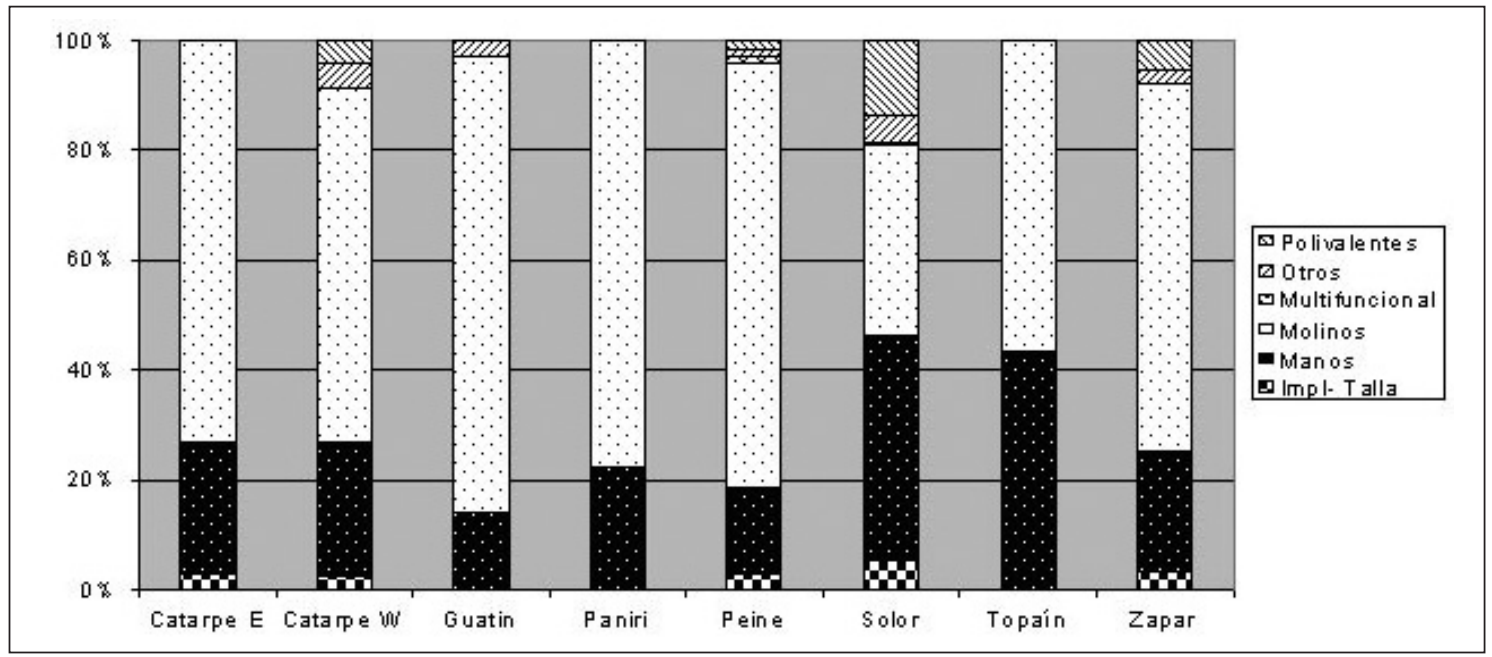

Gráfico 1. Frecuencia de categorías funcionales de artefactos de molienda en sitios tardíos.

Norte, Vilama Sur, Quitor, Zapar, Catarpe Este, Catarpe Oeste, Peine, Topaín y Paniri (Figura 1).

Guatin está ubicado $25 \mathrm{~km}$ al norte de San Pedro de Atacama en la confluencia de los ríos Puripica y Puritama. Se inserta dentro de un sistema estanciero con un uso fundamentalmente agrícola (Adán 2003), sin descartarse actividades de pastoreo como estaría demostrado en acumulaciones de guano registradas en algunas unidades excavadas (Serracino y Stehberg 1974).

Los sitios de Campos de Solor se localizan en el oasis de San Pedro de Atacama, al oriente de los ayllu de Solcor y Solor, sobre la planicie de origen pliocénico afectada por la actividad fluvial del río Vilama. El patrón nucleado de este asentamiento se interdigita con los sistemas estancieros e inicios de ocupación en sectores de quebradas, todo lo cual formaría parte del mismo proceso cultural (Adán 2003).

El sitio de Vilama se ubica a unos $5 \mathrm{~km}$ al norte de San Pedro de Atacama, sobre dos mesetas altas escarpadas y de difícil acceso, en un sector de estrechamiento de la quebrada del río Vilama, en la confluencia con una quebrada seca. Es un lugar eminentemente estratégico, puesto que está estrechamente vinculado a la desembocadura al Salar, de tal manera que permite control y completa visibilidad sobre este recurso hídrico permanente (Adán 2003). Se compone de dos sectores separados por la quebrada seca que han sido

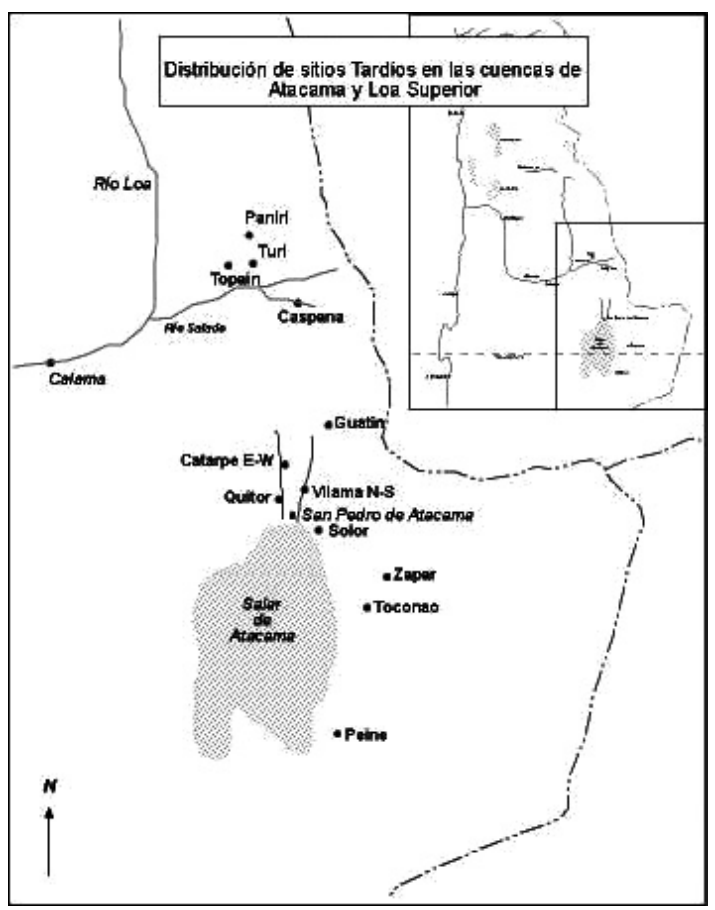

Figura 1. Distribución de sitios tardíos en las cuencas de Atacama y del Loa Superior.

llamados Vilama Norte y Vilama Sur. Ambos conjuntos se han edificado sobre una planicie con una leve inclinación y en su extremo sur presentan un muro defensivo, de hilada doble y relleno, y con presencia de troneras. En el caso de Vilama Norte, al interior del muro, aún se conservan concentraciones de piedras a modo de proyectiles acu- 
mulados con fines de beligerancia o defensivos. Se enmarca, por tanto, dentro del tipo de arquitectura defensiva local (Adán 2003).

El sitio Catarpe se ubica a $7 \mathrm{~km}$ al norte de San Pedro de Atacama sobre tres terrazas correspondientes a la Cordillera de la Sal, y al borde del río San Pedro. Se asocia a extensos campos de cultivo en el valle del río y a una ruta de tránsito que une a esta zona con el Loa Superior y de allí con el altiplano boliviano. Asimismo, su localización controla el recurso hídrico del río San Pedro en el sector más importante de la cuenca del Salar (Lynch y Núñez 1994). Comprende dos conjuntos edificados bastante bien diferenciados entre sí, correspondientes a los sitios denominados Catarpe Este y Catarpe Oeste. Ambos presentan un trazado claramente ortogonal sobre una meseta plana, reproduciendo elementos clásicos de la arquitectura inca. Sin embargo, Catarpe Oeste se edifica casi en la totalidad de la meseta que forma la terraza donde se emplaza, mientras que Catarpe Este deja una importante superficie sin edificar. En este sentido se observa una clara intención de construir dos conjuntos separados, de los cuales Catarpe Este soportaría en términos de superficie los recintos de Catarpe Oeste, con funciones y características distintas. Además, se diferencian por la presencia de un importante cementerio asociado a Catarpe Oeste y extensas plazas en Catarpe Este (Adán 2003).

El sitio Peine o "Peine Viejo" se ubica a $120 \mathrm{~km}$ aproximadamente al sur de San Pedro de Atacama, en el extremo meridional del Salar y contiguo al actual pueblo de Peine emplazado en un ámbito de quebradas que comienzan a ascender hacia las cumbres andinas, a una altura cercana a los 2.200 m.snm. Peine resulta particularmente relevante dado que es uno de los últimos asentamientos humanos antes de adentrarse en el Despoblado de Atacama, posición que debió ser valorada durante todos los momentos prehispánicos especialmente tardíos y reforzada por la lógica de extensión política y territorial del Tawantinsuyo (Adán 2003). El asentamiento está edificado en una meseta, limitada por pequeñas quebradas secas que determinan una planicie levemente inclinada. Se registraron 210 recintos edificados en piedra, distribuidos en una superficie aproximada de 1.6 ha. Las estructuras se construyeron siguiendo la orientación longitudinal de la meseta en un sentido O-E ubicándose en el extremo occidental la iglesia y una calle, elementos que han servido para caracterizar la ocupación hispana colonial del asentamiento (Adán 2003).

Zapar se ubica al norte de Toconao, a $32 \mathrm{~km}$ al sur de San Pedro de Atacama en la quebrada homónima, formando parte del conjunto de quebradas que asciende desde el valle longitudinal hacia las cumbres andinas. Tal emplazamiento, asociado a ciertos elementos constructivos, como las estructuras de patrón constructivo tipo chullpa y los entierros en cistas entre otros, relacionan a este sitio con una tradición de tierras altas acercándolo formalmente al sitio de Likan, representante de la influencia Altiplánica o Fase Toconce en el Loa Superior (Adán 2003).

Por su parte, Topaín está ubicado en la ladera noreste de un cerro isla del mismo nombre entre las localidades de Turi y Cupo en la Subregión del río Salado, Loa Superior. El sitio de patrón nucleado es mencionado por Mostny (1949), quien lo describe brevemente como de construcciones similares a las de Turi, llamándolo "Pucara de Cupo". No detalla materiales, pero advierte que se encuentra en mejores condiciones y menos saqueado que Turi. En tanto, Pollard (1970) lo asigna al Complejo Lasana.

Finalmente, Paniri se emplaza frente a las localidades de Turi, Aiquina y Cupo, a los pies del volcán del mismo nombre. Corresponde a un asentamiento de carácter estanciero y nucleado. Alliende y colaboradores (1993) sitúan al complejo sitio de Paniri dentro de la Fase Toconce apoyándose en la cerámica, arquitectura chullparia, sepultura en abrigos rocosos y en el desarrollo del sistema agro hidráulico.

Sanhueza y Uribe (2002 Ms) han propuesto un ordenamiento de estos sitios a partir de la frecuencia de los tipos cerámicos presentes, el que tiene connotaciones tanto temporales como funcionales. Así, los sitios Guatin, Solor, Vilama Norte y, probablemente, Vilama Sur representarían un primer momento del Período Intermedio Tardío, en tanto que Catarpe Este, Catarpe Oeste y Quitor se corresponden con uno posterior, más "clásico" recibiendo posteriormente el impacto del Inka, lo que es claro y evidente en Catarpe Este. Zapar y Peine también pudieron haber sido ocupados en forma contemporánea a Quitor y Catarpe Este y Oeste, pero serían los únicos que perdurarían hasta 
momentos posteriores, extendiéndose su ocupación incluso hasta momentos de la colonia temprana. Del mismo modo, y aunque preliminarmente, los sitios del Loa Superior también evidencian momentos disímiles dentro del período, siendo Topaín exponente de un momento inicial, mientras que Paniri representa un momento posterior y de contacto con el Inka, evidenciado sólo al observar su arquitectura (estructuras de patrón constructivo tipo chullpa y muros dobles).

Dos de estos sitios, Quitor y Vilama Norte, no presentaron material de molienda, lo que no quiere decir que nunca lo hayan tenido, ya que es bastante probable, dadas las condiciones de exposición y las visitas turísticas a los sitios (especialmente en el caso de Quitor), que estas piezas fuesen sacadas del lugar por terceros. A propósito, Mostny (1949) advierte sobre la presencia de piedras de moler en algunos recintos del Pucara de Quitor, al mismo tiempo que los describe fracturados e insistiendo en lo visitado que es el sitio, en donde los turistas se llevan los materiales de superficie. Esta resulta una buena explicación para la ausencia de este tipo de material en un sitio donde los restos vegetales resultan bastante significativos (González 2003).

\section{El registro artefactual intrasitio}

\section{Los sitios del Salar de Atacama}

En Guatin, a pesar de la cantidad de materias primas y otros restos líticos que se encuentran repartidos en superficie, los instrumentos de molienda son escasos. Se detectó un total de 36 piezas, las que se distribuyeron en las categorías correspondientes a conanas, morteros, metates, manos y "piedra plana de función indeterminada". No se registraron otros instrumentos como machacadores y percutores, relacionados con la presencia de molinos. Este hecho puede ser explicado, en parte, por las condiciones de depósito y la alteración agrícola subactual que ha sufrido el sitio, lo que habría dispersado las piezas rodadas a sectores donde la identificación se hace imposible, ya que además se encuentra expuesto a los lechos y crecidas de las quebradas donde se emplaza.

Llama la atención la regularidad de las frecuencias, registrándose diez de cada una de las categorías correspondientes a molinos en su parte inmóvil, cinco manos de moler y una piedra de pe- queñas dimensiones, plana y pulida de función indeterminada en cuya cara dorsal se observa pigmento rojo. No obstante, no existe ninguna distribución espacial de los artefactos a la que se pudiera identificar como un área de actividad, no registrándose concentraciones de más de tres instrumentos en un solo recinto.

Según González (2003), este sitio ofrece escasos restos vegetales destacándose únicamente los restos de chañar que se encuentran en la mayoría de los recintos muestreados. Esto se contrapone, en parte, con la connotación eminentemente agrícola del asentamiento; no obstante, resulta coherente con la presencia relativamente escasa de materiales de molienda. Al respecto, podríamos suponer que el despliegue de la actividad agrícola de Guatin pretende subsanar un problema de escasez donde una estrategia extensiva no logra la suficiente intensidad en la obtención del recurso agrícola; o bien, este sistema estanciero contempla únicamente la producción, quedando fuera del sitio las actividades de almacenaje y procesamiento de alimentos. En este sentido, aquí se habrían desarrollado sólo algunas actividades básicas y minoritarias no centralizadas, y únicamente para un número limitado de habitantes lo que quedaría demostrado por la escasa concentración de instrumentos en los recintos.

En Campos de Solor se registraron 351 instrumentos provenientes de cinco conjuntos muestreados, de los cuales Solor-4 es el que presenta la mayor cantidad. Estos alcanzan las 159 unidades, mientras que en Solor-16 el número se eleva a 107 piezas. En tanto, Solor-14 cuenta con 56 y Solor-12 con 19 artefactos. En Solor-21, donde se reconoció más de un sector trabajándose sólo el central de éstos, se registró un total de diez artefactos. Asimismo, es en Solor-4, donde existe un número importante de piezas concentradas en un sector $(n=40)$, lo mismo que en Solor-16 donde se concentran 33 piezas en un único recinto, evidenciándose en éstos, posibles áreas de actividad especifica asociada a tales artefactos.

La Tabla 1 muestra las categorías y tipos registrados, considerando tales conjuntos como una unidad (o como un único sitio). La alta frecuencia de manos, parte móvil de los procesos de molienda, sumado al bajo número de piezas correspondientes a la contraparte de éstas o parte inmóvil, hace pensar en el uso de estos artefactos en funciones 
desvinculadas de la molienda, no determinadas por el momento. Aunque también es probable, por lo expuesto que se encuentra el sitio, que las piezas más llamativas hayan sido sacadas del lugar por acción de terceros. A favor de la primera posibilidad contribuye la escasa presencia de restos vegetales recolectados, los que se limitan a algunas ramas no identificadas y a algunas pocas semillas de chañar (González 2003). No obstante, esta información debiera ser revaluada en investigaciones futuras con estudios estratigráficos, ya que por las mismas condiciones de exposición del sitio, tales restos pudieron desaparecer por agentes de erosión naturales como la lluvia y el viento.

En Solor también es recurrente la presencia de instrumentos con más de una funcionalidad, la que se relaciona con el retomado o reutilización de las piezas, lo que va desde una función original y principal como la molienda, a una secundaria como la talla lítica. Con esto no se quiere decir que la actividad de talla sea secundaria en términos de importancia, sino que los artefactos reutilizados en esta actividad no han sido originalmente concebidos para tales efectos. Esto también evidencia una importante actividad de talla lítica, probablemente con técnica bipolar a juzgar por la reutilización de diversas piezas como yunques.

\begin{tabular}{|c|c|c|c|}
\hline CATEGORIAS & TIPOS & TOTAL & $\%$ \\
\hline Impl.- Talla & Yunque & 19 & 5.41 \\
\hline \multirow[t]{2}{*}{ Manos } & Machacador & 17 & 4.84 \\
\hline & Mano & 113 & 32.19 \\
\hline \multirow[t]{3}{*}{ Molinos } & Conana & 56 & 15.95 \\
\hline & Metate & 20 & 5.70 \\
\hline & Mortero & 45 & 12.82 \\
\hline Mult.- Móvil & Mano-Machacador & 14 & 3.99 \\
\hline Multifuncional & Mortero-Mano & 1 & 0.28 \\
\hline \multirow[t]{2}{*}{ Otros } & N/D & 8 & 2.28 \\
\hline & Pala & 10 & 2.85 \\
\hline \multirow[t]{5}{*}{ Polivalentes } & Mano-Machacador- & & \\
\hline & Yunque & 4 & 1.14 \\
\hline & Mano-Martillo & 1 & 0.28 \\
\hline & Mano-Yunque & 37 & 10.54 \\
\hline & Yunque-Machacador & 6 & 1.71 \\
\hline \multicolumn{2}{|l|}{ Total } & 351 & 100 \\
\hline
\end{tabular}

Tabla 1. Frecuencia de categorías de artefactos de molienda en Solor.
En Vilama sólo se registraron materiales en el sector sur, donde apenas se reconocieron una mano de moler, un machacador, una manomachacador, un mortero y un percutor. La escasez de material puede estar ligada al tipo de sitio (defensivo); a las investigaciones realizadas con anterioridad en el lugar o a la acción de terceros. Por otra parte, tampoco se registran importantes restos vegetales (González 2003), lo que sumado a la expeditividad y función del emplazamiento resulta bastante coherente con lapsos de ocupación determinados y en momentos específicos, generando un escaso depósito de artefactos de molienda.

En Catarpe Oeste (Tabla 2) se registraron 116 piezas correspondientes a distintas categorías. No obstante, no se produce de manera tan evidente la reutilización de instrumentos, sino que éstos cumplen básicamente con una única función. Asimismo, no se observan concentraciones significativas de artefactos en ningún recinto o sector determinado del sitio, no habiendo más de cinco ejemplares en tres recintos tanto en sus sectores interiores y exteriores, por lo que no habría en Catarpe Oeste lugares especialmente destinados para desarrollar actividades de molienda.

Debido al estado de deterioro en que se encuentra el sitio, es posible que estas cantidades no reflejen de manera muy certera la situación de estos artefactos en momentos prehispánicos, pudiendo

\begin{tabular}{|c|c|c|c|}
\hline CATEGORIAS & TIPOS & TOTAL & $\%$ \\
\hline Impl.- Talla & Percutor & 3 & 2.59 \\
\hline \multirow[t]{2}{*}{ Manos } & Machacador & 1 & 0.86 \\
\hline & Mano & 27 & 23.28 \\
\hline \multirow[t]{3}{*}{ Molinos } & Conana & 50 & 43.10 \\
\hline & Metate & 19 & 16.38 \\
\hline & Mortero & 4 & 3.45 \\
\hline Mult.- Inmóvil & Metate-Conana & 2 & 1.72 \\
\hline \multirow[t]{2}{*}{ Otros } & N/D & 4 & 3.45 \\
\hline & Pulidor & 1 & 0.86 \\
\hline \multirow[t]{2}{*}{ Polivalentes } & Mano-Yunque & 4 & 3.45 \\
\hline & Metate-Yunque & 1 & 0.86 \\
\hline \multicolumn{2}{|l|}{ Total general } & 116 & 100 \\
\hline
\end{tabular}

Tabla 2. Frecuencia de categorías de artefactos de molienda en Catarpe Oeste. 
quizás haber muchas piezas utilizadas en la construcción de los muros, hoy derrumbados.

Catarpe Este registró una cantidad considerablemente menor de instrumentos destinados a la actividad de molienda, los cuales sumaron 67 unidades, observándose una importante diferencia respecto de Catarpe Oeste, tanto en cantidades como en tipos de artefactos representados (Tabla 3).

A partir de estas discrepancias es posible suponer diferencias en los tipos de productos a moler, o bien, en el tratamiento a que éstos son sometidos en uno u otro sitio. Aunque por otro lado, como lo hemos señalado, muchas de las piezas pudieron estar formando parte de los muros hoy derrumbados, por lo que también es posible que Catarpe Este, sitio de mayor filiación incaica, se haya construido sobre un sector previamente ocupado por poblaciones más tempranas (a juzgar por la mayor presencia de morteros, y si se acepta que éstos han sido considerados como más característicos de períodos previos). Por ahora, es más probable asumir una diferencia de carácter funcional, en el sentido de que Catarpe Este posee más espacios públicos destinados a actividades ceremoniales, mientras que Catarpe Oeste ofrece un ambiente más habitacional, lo que establece formas más específicas de productos a moler (p.e., chicha, minerales, etc.).

Por otra parte, en Catarpe Este tampoco se observan sectores o recintos especialmente destinados para el desarrollo de la actividad de molienda, ya que no se agrupan por más de dos o tres en cada recinto, registrándose sólo un caso en que los artefactos se agrupan en número de cinco constituyéndose como la mayor concentración, aun cuando es bastante baja como para determinar un sector de actividad especializada. Del mismo modo, no se observa reutilización de artefactos, por lo que estos cumplirían sólo con una función predeterminada.

El sitio de Peine también ofrece una cantidad importante de piedras de moler, alcanzando a 166 piezas. Sin embargo, las mayores frecuencias están dadas por las conanas y las tacitas. El resto de las categorías aparece escasamente representado, aunque evidenciando una amplia e importante variedad de tipos relacionados con eventos de reutilización y multifuncionalidad (Tabla 4).

\begin{tabular}{|l|l|r|c|}
\hline CATEGORIAS & \multicolumn{1}{|c|}{ TIPOS } & TOTAL & \% \\
\hline Impl.- Talla & Percutor & 2 & 2.99 \\
Manos & Mano & 16 & 23.88 \\
\multirow{2}{*}{ Molinos } & Conana & 9 & 13.43 \\
& Metate & 23 & 34.33 \\
& Mortero & 16 & 23.88 \\
Mult.-Inmóvil & Conana-Mortero & 1 & 1.49 \\
\hline Total general & & $\mathbf{6 7}$ & $\mathbf{1 0 0}$ \\
\hline
\end{tabular}

Tabla 3. Frecuencia de categorías de artefactos de molienda en Catarpe Este.

\begin{tabular}{|l|l|r|r|}
\hline CATEGORIAS & \multicolumn{1}{|c|}{ TIPOS } & TOTAL & \multicolumn{1}{c|}{$\%$} \\
\hline Impl.- Talla & Percutor & 4 & 2.41 \\
Manos & Machacador & 3 & 1.81 \\
& Mano & 21 & 12.65 \\
Molinos & Conana & 45 & 27.11 \\
& Metate & 25 & 15.06 \\
& Mortero & 8 & 4.82 \\
& Preforma conana & 1 & 0.60 \\
& Tacita/preforma & 1 & 0.60 \\
Mult.-Móvil & Tacita & 48 & 28.92 \\
Mult.-Talla & Mano-Machacador & 1 & 0.60 \\
& Mano-Núcleo & 1 & 0.60 \\
Multifuncional & Munque-Percutor & 1 & 0.60 \\
& Metate-Mano & 1 & 0.60 \\
& Mortero-Mano & 1 & 0.60 \\
Otros & Hacha & 1 & 0.60 \\
& Pala & 1 & 0.60 \\
Polivalentes & Machacador-Percutor & 2 & 1.20 \\
& Mano-Percutor & 1 & 0.60 \\
\hline \multirow{2}{*}{ Total general } & & $\mathbf{1 6 6}$ & $\mathbf{1 0 0}$ \\
\hline
\end{tabular}

Tabla 4. Frecuencia de categorías de artefactos de molienda en Peine.

Resulta importante destacar, en relación a las piedras tacitas, la variedad de tipos identificados. Todas están labradas en los bloques de roca natural del sitio correspondiente a un estrato rocoso de grano fino y color blanco a gris, opaco y de textura áspera. Los orificios se encuentran aislados así como agrupados en conjuntos, en bloques fijos imposibles de mover y en bloques que han sido removidos para ser llevados a distintos sec- 
tores del sitio. Si bien, la Tabla 4 indica la presencia de 48 de estos artefactos, se debe señalar que esta cifra hace referencia a conjuntos en donde es posible apreciar grupos de dos, tres, cuatro $\mathrm{y}$ cinco orificios. Asimismo, un único orificio puede contener a su alrededor varias otras caras de fricción, es decir, orificios menores dispuestos alrededor de un orificio mayor uno al lado de otro hasta completar la vuelta completa al central. De este modelo se encuentran depresiones secundarias en conjuntos de hasta siete, sin desmedro de que una pieza de estas características tenga a su lado, y formando parte del mismo conjunto, a otra de similares características, lo que genera sectores de presencia intensiva de este artefacto. Estos sectores se registran principalmente al borde de la quebrada sur que limita el sitio.

Gran parte de las tacitas son bastante profundas, alcanzando hasta los $25 \mathrm{~cm}$ de profundidad, y por lo general son cilíndricas y en menor cantidad cónicas. También se encuentran ejemplares alargados (como en Zapar), y otros recién iniciados, lo que determina profundidades de $2 \mathrm{~cm}$ y en algunos casos círculos pulidos a ras de la roca. Por último, cabe señalar la presencia de tacitas "agotadas", es decir, que ya han sobrepasado los límites de su vida útil, y que el orificio ha traspasado el estrato rocoso alcanzando el depósito de tierra que se encuentra bajo éste.

Respecto de las tacitas, Mostny señala que los habitantes de Peine les llaman "tacanas", notando que su distribución es irregular así como su tamaño:

"Los hay de a una y en grupos de a varias. El grupo mayor consiste en seis tacitas; la más grande tiene $0.25 \mathrm{~m}$ de diámetro por $0.3 \mathrm{~m}$ de profundidad; la más pequeña tenía solamente $0.07 \mathrm{~m}$ de diámetro y $0.02 \mathrm{~m}$. de profundidad y es aparentemente una tacita recién empezada a trabajar. Otra tacita tenía al lado dos más pequeñas y menos profundas" (1949: 193).

En cuanto a las conanas, estas piezas son muy comunes, y con la particularidad de ser bastante profundas, situación que también se registra en Zapar, además de la presencia en algunos casos de más de una cara de fricción. Esto es posible gracias al tamaño de las piezas. Otro hecho importante es el grado de fractura y fragmentación: casi no hay registro de piezas completas (sólo se identificó una conana completa), lo que podría corresponder a ejemplares intensamente utilizados.
Por otra parte, existe una distribución homogénea de los materiales dentro del sitio, con la salvedad de las tacitas concentradas básicamente al borde la quebrada mencionada, ubicándose las piezas fundamentalmente al exterior de los recintos.

La molienda en Zapar. Este sitio fue tratado separadamente del resto debido a la gran cantidad de materiales registrados, los que alcanzan a 459 piezas distribuidas en las categorías de metates, conanas, morteros, tacitas, yunques, manos, percutores, machacadores y no determinables. Cada una de estas categorías representa una forma y una función determinadas, pero en muchos casos se advirtió que las piezas cumplían más de un uso específico, alcanzando una doble y hasta triple funcionalidad.

El tipo de artefacto más representado es la conana con un $47 \%$ de las frecuencias del total de unidades $(n=216)$. Respecto de este instrumento cabe señalar que se pudieron identificar piezas en distintas etapas del proceso de vida útil registrándose conanas en el inicio de manufactura, con la superficie principal plana y deprimida piqueteada, lo que constituye eventuales preformas de estos instrumentos; otras en la misma situación, pero además con inicio del pulido por uso sobre la pieza; instrumentos completos; desgastados completamente, y finalmente descartados, fracturados, y hasta reutilizados en la construcción de los muros del sitio. Sin embargo, una gran cantidad $(n=192)$ se encuentra fracturada.

Además, se detectó que el $70 \%$ de conanas $(n=150)$ presenta la cara y concavidad de fricción pulida, lo que indica instrumentos terminados y en estado avanzado de utilización. El $12 \%$ se encuentra piqueteado por uso, lo que es advertido por una concavidad profunda y piqueteada sobre el pulido. El piqueteado por manufactura (7\%) señala las preformas, es decir, piezas apenas deprimidas por piqueteo y no pulidas. El $6 \%$ y $5 \%$ corresponden a piezas pulidas y piqueteadas por uso, así como pulidas y piqueteadas por manufactura, respectivamente. A estas últimas, es probable que se les aplicara este tipo de desgaste para mantener las superficies de fricción más activas. También se detectaron conanas con más de una superficie de fricción: 13 piezas con dos concavidades, una con tres y un caso con cuatro concavidades. Si bien siempre existe una concavidad más profunda, que es la principal, es notorio el des- 
gaste por uso en más de una superficie de la pieza (Figura 2).

El otro instrumento de molienda con mayor representación en Zapar es la mano de moler (Tabla 5). Esta corresponde a piezas cuya única funcionalidad es la de moler, no contándose aquellas con más de una funcionalidad o retomadas. El desgaste en estas piezas incluye el uso facial, lateral, distal, bifacial, bilateral y bidistal, al mismo tiempo que combinaciones de estos atributos en una misma pieza. Además, cumplen la funcionalidad de molinos como parte móvil del proceso de molienda los machacadores que suman apenas cuatro ejemplares alcanzando al $1 \%$.

Se deben agregar también las piezas multifuncionales, multifuncionales-móviles y polivalentes como las manos-machacadores, manos-yunques, manos-percutores-machacador, mano-machacadoryunque, metates-machacadores y manos-machacadores-percutores-yunques. Es decir, en términos generales, se registraron 123 piezas correspondientes a la parte móvil del proceso de molienda, entre las que se observan desde una hasta cuatro funciones.

Los yunques y los percutores, se registran de manera escasa y están más bien relacionados a la talla lítica, y más específicamente a la percusión bipolar, la que es bastante pobre en el sitio. Por otra parte, los instrumentos polivalentes, que presentan uso como yunques y/o percutores, corresponderían a piezas retomadas, por lo que no sería ninguna de éstas su función original, sino que más bien se ligarían a episodios de molienda, y de manera anexa y/o secundaria a la talla. Esto, considerando la importancia de cada una de estas actividades dentro del sitio. Por lo tanto, el retomado y la reutilización de piezas son acontecimientos frecuentes en el sitio, y van desde una actividad principal como es la molienda a una secundaria como la talla lítica.

En cuanto a la distribución de los artefactos dentro del sitio, se observaron piezas al interior y exterior de recintos, como parte de los muros y sobre éstos. Doscientos cuarenta y dos unidades se registraron al interior de los recintos, 94 al exterior, 92 formando parte de los muros y 31 sueltas sobre éstos, lo que indica remociones tardías de los instrumentos. Las características propias del yacimiento, compuesto por conjuntos aglomerados de re-

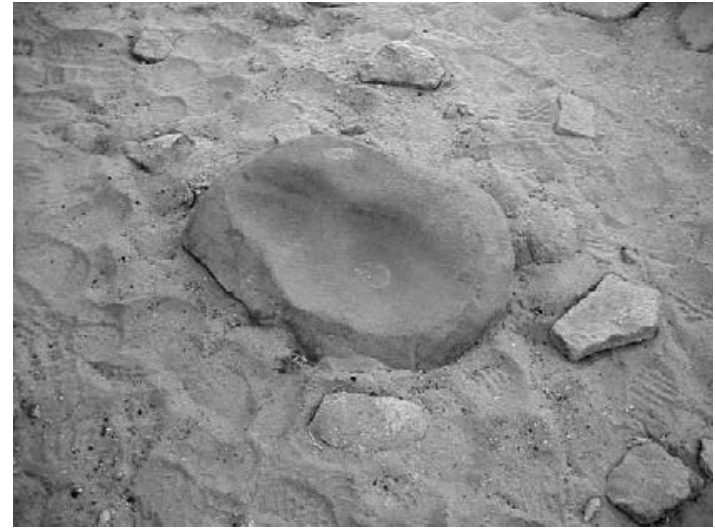

Figura 2. Molino con más de una cara de uso (Zapar).

\begin{tabular}{|c|c|c|c|}
\hline CATEGORIAS & TIPOS & TOTAL & $\%$ \\
\hline \multirow[t]{2}{*}{ Impl.- Talla } & Percutor & 9 & 1.96 \\
\hline & Yunque & 6 & 1.31 \\
\hline \multirow[t]{2}{*}{ Manos } & Machacador & 4 & 0.87 \\
\hline & Mano & 83 & 18.08 \\
\hline \multirow[t]{4}{*}{ Molinos } & Conana & 216 & 47.06 \\
\hline & Metate & 32 & 6.97 \\
\hline & Mortero & 42 & 9.15 \\
\hline & Tacita & 6 & 1.31 \\
\hline \multirow[t]{2}{*}{ Mult.-Inmóvil } & Conana-Mortero & 9 & 1.96 \\
\hline & Metate-Conana & 1 & 0.22 \\
\hline Mult.- Móvil & Mano-Machacador & 13 & 2.83 \\
\hline Mult.- Talla & Yunque-Percutor & 1 & 0.22 \\
\hline Multifuncional & Metate-Machacador & 1 & 0.22 \\
\hline Otros & N/D & 10 & 2.18 \\
\hline \multirow[t]{8}{*}{ Polivalentes } & Mano-Machacador- & & \\
\hline & Percutor & 1 & 0.22 \\
\hline & $\begin{array}{l}\text { Mano-Machacador- } \\
\text { Yunque- Percutor }\end{array}$ & 1 & 0.22 \\
\hline & Mano-Machacador- & & \\
\hline & Yunque & 2 & 0.44 \\
\hline & Mano-Percutor & 8 & 1.74 \\
\hline & Mano-Yunque & 12 & 2.61 \\
\hline & Metate-Yunque & 2 & 0.44 \\
\hline \multicolumn{2}{|l|}{ Total general } & 459 & 100 \\
\hline
\end{tabular}

Tabla 5. Frecuencia de artefactos de molienda en Zapar.

cintos, hacen que los exteriores de unos sean los interiores de otros, lo que explica la escasa presencia de instrumentos al exterior de recintos y, por ende, la alta presencia de éstos en los interiores. 
También resulta significativo el número de piezas que se encuentra formando parte de la construcción de los muros, lo que puede estar indicando un alto grado de reconstrucción de los mismos. Más aún, si consideramos que muchos de estos artefactos se ubican muy abajo en los muros, e incluso cerca de las bases de éstos, se advierte que, probablemente, los eventos de reconstrucción del sitio se han llevado a cabo desde momentos muy tempranos de ocupación, manteniéndose hasta épocas tardías, y tal vez hasta subactuales. También es posible que muchas de las piezas registradas al interior como en el exterior de los recintos, hayan formado parte de los muros, y que hoy se encuentran en superficie debido a eventos de derrumbe. Es probable que en Zapar la molienda desde siempre haya significado una actividad importante, incluso en períodos previos a su construcción, y que muchos de los artefactos desgastados y abandonados se hayan utilizado para la construcción del sitio. No es extraño pensar en reocupaciones sucesivas del emplazamiento, más aún si consideramos que este tipo de situaciones también son conocidas y reiterativas en la región del Loa Superior, en donde varios de los sitios tardíos muestran evidencias de ocupación del Período Formativo (Uribe y Carrasco 1999).

Por otra parte, existen al menos tres recintos en donde se ha concentrado una importante cantidad de piezas (más de 20 unidades en cada caso), especialmente en sus sectores exteriores configurando lo que se podría suponer como sectores especialmente destinados para el desarrollo de la activad de molienda, aun cuando también se encuentran otros recintos con importantes cantidades de artefactos en sus sectores interiores. De este modo, es posible señalar que en Zapar hubo determinados espacios en donde la molienda se practicó de manera sistemática, aunque la presencia de instrumentos en todo el sitio es recurrente, por lo que ésta sería una de las prácticas económicas fundamentales dentro del asentamiento.

Se debe destacar, además, la presencia de seis conjuntos de "tacitas" distribuidos hacia las afueras del sitio y en los bordes de las quebradas circundantes. Un primer conjunto está ubicado hacia el borde de la quebrada de Zapar, cuenta con seis concavidades conectadas en dos grupos de tres cada uno. El conjunto 2 también ubicado ha- cia el borde de la quebrada de Zapar, es el más grande, y cuenta 18 concavidades conectadas en dos grupos de cuatro, dos de tres, uno de dos y dos aisladas en los extremos este y oeste del conjunto (Figura 3). El tercero cuenta seis concavidades, todas aisladas, hacia la quebrada de Zapar. El conjunto 4 corresponde a una única tacita aislada ubicada al borde de la quebrada de Zapar unos $5 \mathrm{~m}$ al oeste del conjunto 2 , y a unos $3 \mathrm{~m}$ al norte del conjunto 3 . El conjunto 5 presenta dos tacitas aisladas y, por último, el conjunto 6 suma tres tacitas conectadas ubicadas hacia el borde de la quebrada que al sur limita al sitio.

El conjunto 2 aquí descrito es detallado por Mostny (1949: 184) quien publica una fotografía y un dibujo a escala, situándolos en la misma entrada del pueblo. Al igual que en este texto, observa una serie de 18 pequeñas hendiduras artificiales de escasa profundidad: "Tienen aproximadamente 0.24 a $0.28 \mathrm{~m}$ de largo por 0.16 a 0.22 $\mathrm{m}$ de ancho y $0.1 \mathrm{~m}$ de profundidad y son arregladas en varias hileras. En total cubren una superficie de 1.7 a $1.8 \mathrm{~m}$ ". La autora hace notar el parecido con las piedras tacitas de la zona central de Chile; no obstante, advierte que la forma de la hendidura es diferente, ya que las tacitas son producidas por un movimiento rotativo vertical que les da la forma de cono invertido o de taza, mientras que las de Zapar "son producidas por el mismo movimiento que produce la cavidad en los morteros: un movimiento horizontal con el cual se ejerce, al mismo tiempo, una ligera presión sobre el fondo de piedra" (Mostny 1949: 184). Respecto de su significado, la autora hace mención a Uhle quien las considera como morteros comunales, mientras que Latcham cree que son

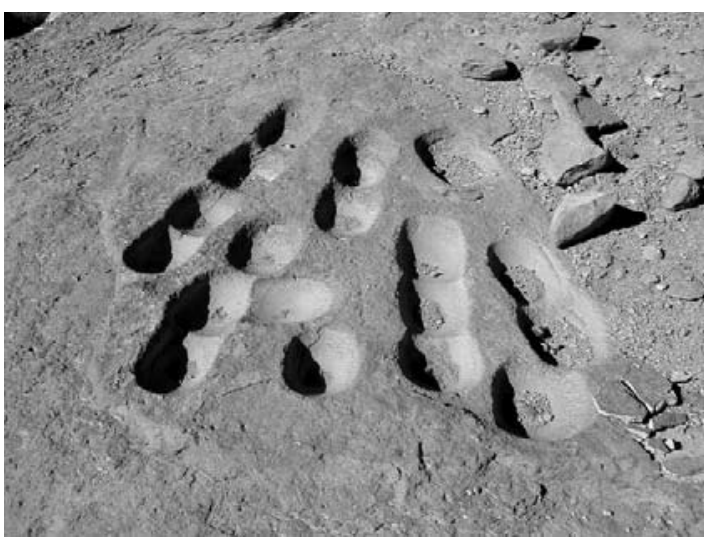

Figura 3. Conjunto 2 de tacitas en el sitio Zapar. 
rituales debido a su forma poco práctica para moler, su distribución en áreas habitadas y deshabitadas, su gran número en espacios tan reducidos, lo que habría dificultado el uso de más de una cavidad a la vez, y a la existencia de piedras con tacitas horizontales (Mostny 1949).

Atendiendo a estas explicaciones, y considerando además las observaciones realizadas por Adán (2003) respecto de la recurrencia de estructuras de patrón constructivo tipo chullpa, se plantea un carácter eminentemente sacro del asentamiento, ligado a la convivencia y culto de los antepasados. Además, la escasa presencia de recintos habitacionales sugiere que se trataría de una aldea con poca capacidad habitacional constante vinculada al desarrollo de actividades religiosas, aglutinadoras social y culturalmente, remitiendo la aldea en su conjunto a la hipótesis funcional descrita para las chullpas de Likán como adoratorios vinculados al culto de los antepasados. En consecuencia, surge la pregunta sobre la funcionalidad de los artefactos de molienda que en este sitio alcanza el mayor registro con relación al resto de los sitios trabajados.

Ya se ha planteado la posibilidad de que una parte importante de las piezas correspondan a episodios más tempranos de ocupación, que no tengan directa relación con los eventos de la aldea propiamente tal, a juzgar por la cantidad de artefactos ocupados en la construcción de los muros, ubicándose incluso en la base de éstos (Figura 4), y también a la importante presencia de instrumentos no completos. No obstante, los recursos vegetales registrados (González 2003) apuntan a una significativa cantidad y variedad (maíz, algarrobo y chañar, principalmente), así como a sectores concentrados de algunas especies en ciertos recintos, coincidentes con los de mayor presencia de instrumental de molienda, entre otros. Esto podría implicar eventos intensivos y masivos de molienda de vegetales, lo que puede estar muy vinculado con la idea de actividades públicas de índole religiosa en el sitio. Por lo demás, en varias de las estructuras tipo chullpa se han identificado enormes cantidades de mineral de cobre molido esparcido en los pisos, tanto interiores como exteriores. En este sentido, cabría suponer que la molienda en Zapar podría estar asociada a eventos especiales de desarrollo de actividades ceremoniales ( $\sin$ desestimar un uso más cotidia-

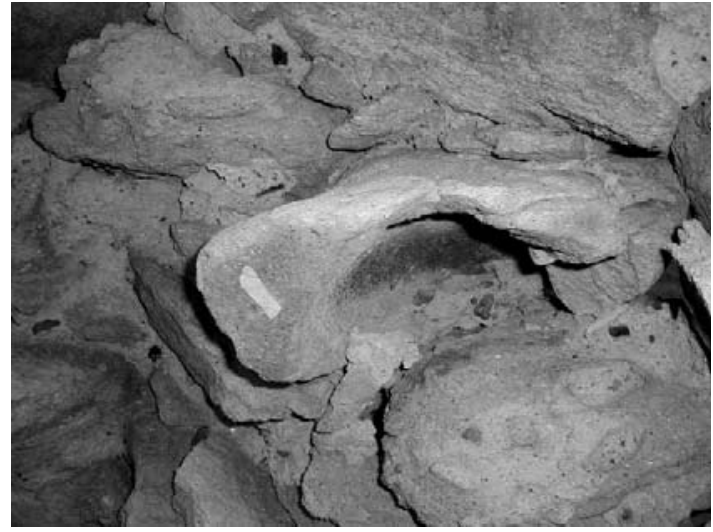

Figura 4. Molino integrado en la construcción de muros (Zapar).

no y económico), cubriendo un amplio espectro de productos a moler donde destacarían los vegetales y minerales.

\section{Los sitios del Loa Superior}

En el Loa Superior se trabajaron los sitios de Topaín y Paniri. El primero de éstos presenta una ocupación con cerámica del Intermedio Tardío, así como una arquitectura relacionada a tal período, no obstante la presencia de un muro con marcadas características incaicas, en tanto que en el segundo es posible observar la presencia del Tawantinsuyo, tanto en la construcción de ciertos recintos así como en el muro norte que flanquea ese extremo del sitio, y en la alfarería de filiación tardía. En este sitio se observa un sector en donde se concentra una serie de estructuras de patrón constructivo tipo chullpa, elemento característico de las tradiciones altiplánicas introducido en las tierras altas de Atacama.

En Topaín sólo se registró un total de 23 artefactos de molienda distribuidos en cuatro categorías (conana, mano, metate y machacador), siendo las conanas las más representadas con 11 unidades. Llama la atención el despliegue tecnológico agrohidráulico de este sitio en contraposición con la escasez de materiales de molienda. Además, sólo una de estas conanas se encuentra completa, registrándose un alto porcentaje de piezas fracturadas $\mathrm{y}$ fragmentos.

Tal situación refleja escasa actividad de molienda y no se evidencian sectores especialmente destinados a tal actividad, lo que permite sugerir que 
ésta habría sido desarrollada por un escaso número de personas y para pequeños grupos.

Tal como muestra la Tabla 6, en Paniri se registró un total de 108 artefactos distribuidos en cinco categorías, siendo las conanas las más representadas. Las similares presencias de metates y morteros recuerdan la situación vista en Catarpe Este, no obstante la importante proporción de conanas en Paniri. La distribución de estos artefactos resulta muy regular hallándose cantidades similares de artefactos tanto dentro como fuera de los recintos y como parte de la construcción de los muros. Sabiendo que el sitio presenta bastantes reconstrucciones y ocupación etnográfica actual, es posible pensar que las piezas puestas en los muros tienen una reutilización más reciente y que probablemente estaban en uso en los períodos que nos ocupan.

Aun cuando el sitio tiene una orientación evidentemente agrícola, no se observan sectores de concentración de actividades de molienda, siendo la distribución de los instrumentos bastante homogénea, lo que sugiere un desarrollo de actividades más bien relacionadas con el ámbito doméstico, en que cada unidad familiar ejerce el uso de éstos dentro de su propio espacio.

En relación a otros sitios de la región del Loa Superior, existe un importante trabajo realizado por Cornejo (1990) en que describe el material de molienda del Pucara de Turi. Este sitio se ubica en las vegas del mismo nombre en la localidad de Aiquina, y corresponde al mayor emplazamiento ocupacional del norte de Chile con más de 600 recintos, presentando tres etapas de ocupación signadas como las fases Turi 1,2 y 3 , que van desde los inicios del Período Intermedio Tardío hasta la colonia temprana (Aldunate 1993).

Cornejo reconoce 388 molinos en todo el sitio, considerando como tales en términos genéricos a todos los artefactos pasivos de molienda, y 74 manos de moler en una recolección superficial que incluyó el $10 \%$ de los recintos del sitio. Del total de 388, 292 piezas corresponden a conanas, 89 a morteros, dos a piedras planas (¿metates?), una a piedra tacita, y cuatro a artefactos imposibles de clasificar debido a su mal estado de conservación. En efecto, el autor nota que más del $60 \%$ de las piezas se encuentran incompletas, mientras las completas no llegan al $15 \%$ de la muestra.

\begin{tabular}{|l|l|r|c|}
\hline CATEGORIAS & \multicolumn{1}{|c|}{ TIPOS } & TOTAL & $\%$ \\
\hline Manos & Mano & 23 & 21.30 \\
Molinos & Conana & 54 & 50.00 \\
& Metate & 19 & 17.59 \\
& Mortero & 11 & 10.19 \\
Mult-Móvil & Mano-Machacador & 1 & 0.93 \\
\hline Total general & & $\mathbf{1 0 8}$ & $\mathbf{1 0 0}$ \\
\hline
\end{tabular}

Tabla 6. Frecuencia de artefactos de molienda del sitio Paniri.

Haciendo un análisis espacial de la distribución de estos artefactos enfocando el tema desde dos perspectivas, ya sea considerando sectores del asentamiento definidos a partir de cuadrantes arbitrarios, y por la asociación de los artefactos con los distintos tipos de recintos en el pucara, Cornejo concluye que es en el sector central del asentamiento donde se concentran más significativamente los instrumentos, dándose las mayores densidades en cinco cuadrantes principales (alcanzando en alguno más de 50 unidades), y específicamente en dos que se corresponden con el centro mismo del sitio. Asimismo, el mayor porcentaje de molinos se encuentra en los recintos angulares, especialmente en aquellos localizados al lado norte del sitio, doblando el porcentaje de cualquiera de los otros tipos de recintos. Los resultados del análisis de este autor apuntan a que existe una distribución de los artefactos definitivamente organizada a partir de las diferencias en las formas de los recintos.

Por otro lado, también detecta una depositación diferencial de las manos y de los molinos, es decir, en los sectores de mayor concentración de molinos no se encuentran manos y, viceversa, lo que tendría que ver con los procesos de uso y descarte de las piezas, es decir, que éstas no se depositan en el mismo lugar donde se usan (Cornejo 1993).

Finalmente, se puede agregar que en la localidad de Caspana, si bien no se han realizado registros sistemáticos de estos materiales, han sido mencionados formando concentraciones especialmente en el sector central del sitio Talikuna, donde además existiría una tacita de grandes proporciones. En este sitio se localizarían principalmente conanas. En Mulorojte, junto con las conanas aparecerían los morteros de hueco cónico. Estos dos 
sitios presentarían ocupaciones locales desde el Intermedio Tardío y "tocadas" por el Inka. Mientras que en Cerro Verde, sitio eminentemente incaico, se identificaron martillos y machacadores, los que estarían vinculados a actividades de extracción y molido de minerales de cobre, el cual además de propiciar un interés especial como tal, es utilizado en la challa a los antepasados en el cementerio de Los Abuelos de Caspana (Uribe y Carrasco 1999).

\section{Connotaciones intersitios}

Como se ha mencionado, los sitios de San Pedro de Atacama han sido ordenados de acuerdo con el registro de la alfarería en los que representan un momento inicial del Período Intermedio Tardío y aquellos donde se desarrollaron eventos en un momento más avanzado o clásico, los cuales, además, recibirían las influencias incaicas más evidentes durante el Período Tardío (Sanhueza y Uribe $2002 \mathrm{Ms}$ )

En el primer conjunto, los sitios de Guatin, Solor y Vilama Sur se presentan bastante heterogéneos en la composición de la muestra. Mientras Guatin, sitio bastante extenso y de marcada orientación agrícola, muestra pocos artefactos de molienda, Solor es uno de los sitios con mayores frecuencias, en tanto que Vilama Sur entrega un panorama similar a Guatin; no obstante, se diferencia de éste por la variabilidad artefactual.

Por otra parte, los sitios de Catarpe Este, Catarpe Oeste, Zapar y Peine, presentan la misma heterogeneidad en cuanto a cantidades; sin embargo, los dos últimos exhiben mayores similitudes. Esta situación hace pensar de inmediato en una estructura de los conjuntos artefactuales relacionada con un efecto funcional en donde tales conjuntos se relacionan a actividades diferenciadas dentro de cada grupo de sitios.

Ya se ha mencionado que dos sitios (Quitor y Vilama Norte) no registraron artefactos de molienda, aunque es probable que alguna vez lo hayan tenido. Sin embargo, es posible pensar en que éste siempre fue escaso, ya que los saqueos no debieran estar dirigidos particularmente a terminar con este tipo de artefactos, por lo cual es más seguro que tales sitios, así como Vilama Sur, constituyan una unidad en términos funcionales debido a las deficientes frecuencias ya descritas. Al respecto, también se puede señalar que en términos de asentamiento como de arquitectura, estos yacimientos ofrecen una funcionalidad bastante clara, determinada por el control y manejo de los recursos hídricos de los dos ríos más importantes para el oasis (Vilama y San Pedro). Ambos, más que defensivos en términos de invasiones foráneas, se vincularían con momentos de crisis y conflictos internos de las poblaciones del Salar (Adán 2003). Suponemos, entonces, que funcionalmente en ellos se desarrollan más comúnmente otras actividades no relacionadas con la molienda. Es posible que el procesamiento de productos a través de esta actividad sea ejecutado sólo por un grupo determinado de personas, mientras el resto de los ocupantes se dedicó a labores propiamente defensivas, directivas, etc.

Guatin, se presenta como un caso especial, donde el desarrollo de una ingeniería agrohidráulica no tiene un correlato material de procesamiento respecto de lo producido. En este sentido, Topaín ofrece la misma característica. Aunque ambas tecnologías agrohidráulicas son básicamente disímiles ("canchones" y terrazas, respectivamente), estos sitios comparten un aspecto similar en el manejo, captación y conducción de las aguas a través de complejos sistemas de canales de regadío. En este punto cabe preguntarse cuál es el rol que estos asentamientos juegan con relación a estas tecnologías, y si es posible que allí sólo se lleve a cabo la producción y algún tipo de almacenamiento de alimentos, en tanto que el procesamiento de éstos se efectúe a pequeña escala y sólo con fines de mantención de los ocupantes, lo que, como en el caso de los sitios de Quitor y Vilama Norte y Sur, haya sido realizado por un pequeño grupo de personas en áreas no centralizadas, constituyéndose de alguna manera con un cierto carácter de grupos de tareas.

A pesar de esta similitud, ambos sitios presentan una diferencia importante relacionada con la variedad de categorías representadas, de tal modo que en Guatin se observan tres tipos de molinos con iguales frecuencias para cada uno de ellos, en tanto que Topaín sólo registra conanas (y un metate, lo que resulta poco significativo). Al respecto, por ahora sólo queda suponer que tales frecuencias se deben a cuestiones funcionales relacionadas al tipo de producto a procesar, y a las capacidades de cada tipo de artefacto para moler uno u otro producto. No obstante, también es po- 
sible hacer un correlato cronológico, aunque con bastante cautela. En efecto, se ha considerado a los morteros de hueco cónico como característicos de momentos tempranos de ocupación, mientras que las conanas harían su aparición a partir del Período Formativo, al menos para el Loa Medio, en asociación directa con la presencia de maíz cultivado (Pollard 1970). Esto significaría que el sitio de Guatin podría tener una ocupación más temprana de la cual haya heredado los morteros, o bien que este sitio mantenga una tradición que se arrastre desde períodos más tempranos, vinculada al uso de este instrumento. No obstante, se reitera la cautela con la que debe tomarse tal proposición, ya que debe recordarse el escaso número de piezas en este asentamiento.

Otros sitios asociados con relación al material de molienda son Catarpe Este y Paniri, los que presentan similares frecuencias de artefactos. En éstos, las cantidades son equivalentes, lo mismo que las variedades con una mínima diferencia de éstas marcada en escasas piezas. Ya antes hemos notado que en Catarpe Este es más nítida la presencia incaica, lo que también es observable directamente en Paniri. Llaman la atención las análogas proporciones de metates y morteros, lo que, vinculado a la hipótesis funcional que hemos manejado, permite señalar algunas situaciones más allá de los eventos de tipo doméstico. Es decir, si se piensa que en los diferentes tipos de molinos se muelen productos distintos, se podría suponer que en estos escenarios con evidente presencia incaica se procesan más bien productos de consumo poco cotidiano (a juzgar por las equivalentes presencias de metates y morteros, en desmedro de las reiteradas conanas, aun cuando Paniri presenta muchas de estas piezas) asociados a eventos ceremoniales vinculados con la arquitectura pública. En este caso, la molienda se desarrollaría como una actividad relativamente masiva, o más bien pública, sin ser necesariamente especializada, en donde distintas categorías de artefactos se utilizarían, eventualmente, para el procesamiento de distintos tipos de productos de acuerdo al requerimiento de circunstancias específicas (¿fiestas?) relacionadas a la presencia incaica en ambos sitios.

Zapar y Peine, además de compartir elementos que los proponen dentro de un mismo conjunto cronológico (p.e., mismos tipos cerámicos y arquitectura de filiación altiplánica, emplazamiento en quebradas y lejanos al oasis de San Pedro de Atacama), pueden ser asociados como afines en el registro del artefactual de molienda, ya que aun cuando en Zapar se reconoce casi el doble de artefactos que en Peine, ambos sitios se comportan similarmente diversificados con análogas frecuencias de categorías. Esto implica que dentro de ambos sitios las actividades relacionadas con estos conjuntos son ejercidas bajo un mismo tipo de organización tecnológica y social. Además, Zapar y Peine son los únicos sitios con tacitas, constituyéndose éstas en otro rasgo tecnológico particular, reafirmando el carácter organizacional similar que comparten ambos asentamientos. De este modo, se podría suponer que es en estos sitios donde se están elaborando más intensivamente productos molidos, lo que no deja de ser significativo considerando que se trata de poblaciones fuertemente vinculadas con tradiciones altiplánicas e incaicas, evidenciando algún eventual tipo de tráfico de productos procesados hacia localidades más distantes.

Por último, cabe señalar que es difícil vincular a Solor con su artefactual de molienda con algún desarrollo específico, ya que cualitativa y cuantitativamente se agrupa mejor con Zapar y Peine. No obstante, tanto los elementos arquitectónicos como cerámicos lo asignan a momentos previos a estos dos sitios. Sin embargo, las sepulturas dentro de estos sitios son un elemento compartido, lo que puede implicar que los restos de molienda depositados estén vinculados con prácticas ceremoniales. Queda también, la posibilidad de que las categorías más representadas en Solor se vinculen a actividades no relacionadas con la molienda, (p.e., preparación de cueros), involucrando cierta organización tecnológica y productiva particular, que haría a este sitio funcionalmente independiente del resto.

\section{Sobre lo procesado}

En cuanto a los elementos potencialmente procesados a través de la molienda que determinarían el uso de la amplia gama de artefactos que hemos descrito, podemos mencionar más certeramente a vegetales y minerales ${ }^{4}$, aun cuando no sean los

\footnotetext{
4 Esto en función de elementos contextuales hallados en los sitios y muestreados ( $20 \%$ del total de recintos de cada sitio en sus sectores interior y exterior).
} 
únicos productos sometidos a estos procesos. Dentro de los primeros, que incluyen a aquellos recolectados y cultivados, es posible separar a los frutos como los más posibles recursos afectados por la molienda. González (2003) establece que en los sitios ${ }^{5}$ los frutos del maíz y el chañar, y las semillas del algarrobo resultan fluctuantes, presentándose las muestras homogéneas a primera vista, ya que se encuentran dentro de cada sitio frecuencias parecidas entre los restos más populares (maíz, chañar y algarrobo).

Al respecto, la autora propone una separación de los sitios en dos grupos, considerando en el primero a Quitor, Catarpe Este, Catarpe Oeste, Zapar y Peine, y en el segundo, a Guatin, Solor, Vilama Norte y Vilama Sur. Las diferencias entre uno y otro grupo parecen estar dadas tanto por la variedad como por las cantidades de restos registrados. Así, el primer grupo ofrece una mayor cantidad y variedad de restos vegetales alcanzando entre los nueve y 14 ítemes distintos, mientras que en el segundo éstos van de dos a cinco.

En cuanto a los elementos más recurrentes, el chañar está presente en prácticamente todos los sitios, y dentro de ellos, en casi todos los recintos recolectados, manteniéndose en la mayoría importantes cantidades, lo que ocurre principalmente en los sitios del primer grupo (Quitor, Catarpe Este, Catarpe Oeste, Zapar y Peine), mientras que en los otros tales cantidades disminuyen.

Por su parte, el maíz está ausente de Guatin, Vilama Sur y Solor, mientras que en Quitor y Peine tiene poca representación, lo mismo que en Catarpe Este y Vilama Norte. En cambio, en Catarpe Oeste y Zapar las cantidades son bastante más elevadas. Finalmente, las semillas de algarrobo también se encuentran en todos los sitios, salvo en Vilama Sur, siendo Catarpe Oeste el que presenta la mayor concentración de éstas, específicamente en dos de los recintos recolectados, involucrando una posible situación de almacenamiento. En Quitor la presencia de estas semillas es también bastante alta, al igual que en Zapar y Vilama Norte. Peine, por su parte, tiene menores cantidades recolectadas (González 2003). ${ }^{6}$

\footnotetext{
5 Los mismos sitios aquí trabajados para el Salar de Atacama, excluyendo aquellos del Loa Superior (Topaín y Paniri).

6 La autora realiza los análisis de cantidades en una relación de peso y cantidad o número de especimenes recuperados.
}

En relación a estos restos vegetales eventualmente expuestos a molienda, Martínez (1998) señala -en términos etnohistóricos- que para el caso de Atacama el maíz, el chañar y el algarrobo se encuentran en un mismo plano de igualdad en cuanto al valor que estos frutos parecen haber tenido para las poblaciones locales. Asimismo, el autor asegura que tanto los bosques como los frutos aparecen reiteradamente en los relatos de quienes han pasado por territorio atacameño, entregando una serie de citas que hacen referencia tanto a la abundancia de chañares y algarrobos, como a la importancia que sus frutos tienen hasta hoy para los habitantes de esta región. En efecto, "ambos árboles parecen haber sido utilizados en actividades diversas, desde el empleo de sus troncos como leña... y como viga para las edificaciones... hasta como ingrediente esencial de la dieta diaria..." (Martínez 1998: 110).

Martínez también señala productos como la miel de chañar (hasta hoy altamente cotizada), y el patai, especie de masa dulce y prensada hecha con harina de algarrobo, además de sendas bebidas fermentadas como el aloja o quilapana, hecha de algarrobo o chañar y usada en las fiestas de índole ritual, y uso durante el trabajo comunitario en el campo, evidenciando de este modo una importante incidencia de estos recursos en la vida cotidiana de la población atacameña. Arqueológica y etnográficamente, también es posible encontrar frutos de chañar y semillas de algarrobo formando parte de las ofrendas funerarias, así como de santuarios de altura, lo que introduce a estos productos en contextos rituales. En efecto, según Martínez, más allá de su importancia alimenticia, energética o incluso económica, pareciera que "lo que realmente manifiesta su importancia es su utilización en una amplia gama de rituales y su valoración como significante de lo sagrado, reconocida aún hoy por las poblaciones atacameñas" (Martínez 1998: 112).

Asimismo, plantea el empleo de ciertas prácticas alimenticias por parte de un grupo, como un elemento útil a otros para calificar la alteridad y clasificarlos étnica o culturalmente. ${ }^{7}$ De este modo, surge la pregunta de si el consumo de chañar y

\footnotetext{
7 El autor pone como ejemplo la denominación de allqomikuq para referirse a los "comedores de perro", y al nombre de urus para los grupos recolectores, entre otras denominaciones.
} 
algarrobo correspondería a un elemento de caracterización cultural o diferenciación étnica con respecto a otros grupos. Siguiendo este argumento, ¿se podría pensar en una diferenciación de tipo cultural relacionada a la mayor o menor presencia de estos restos vegetales en los sitios tratados? Y ampliando la cobertura de esta interpretación, ¿se podría pensar en una diferenciación cultural en relación a las diferentes representaciones de artefactos de molienda de los distintos sitios vinculados a tales recursos? Resulta demasiado precipitado elaborar una respuesta; sin embargo, el ejercicio respecto de algunas connotaciones intersitios podría acercarnos a esta, suponiendo que las relaciones funcionales resultantes implican cierta organización social, que determina estrategias tecnológicas y económicas en cada caso.

Por otra parte, en relación a los minerales, se ha detectado en todos los sitios la presencia en distintas cantidades de mineral de cobre molido y en pequeños trozos. Este mineral también ha tenido importancia desde temprano en las sociedades atacameñas, registrándose ya desde el Arcaico Tardío hasta el Inka siendo utilizado en distintos aspectos de la vida de los grupos, que van desde materia prima para la confección de cuentas de collar y pendientes, hasta la challa en distintos sitios de carácter ceremonial. También, dentro de un ámbito económico, el mineral de cobre ha sido objeto de intercambio o evidencia de interacción entre regiones culturales distantes, lo que se advierte en la presencia de este mineral en áreas donde no es nativo. Además, es conocido el interés del Inka en las minas de cobre de varias localidades del norte de Chile, siendo el sitio de Cerro Verde en Caspana uno de los más importantes asentamientos incaicos de la región (presencia de ushnu), como también una importante fuente de abastecimiento de este mineral para la comunidad local.

Ahora, si bien es posible encontrar mineral de cobre en todos los sitios considerados, se advierte una marcada diferencia de cantidades entre éstos, la que se asocia a la existencia de arquitectura altiplánica en donde este producto es depositado al interior, exterior y frente a los vanos de acceso de las estructuras de patrón constructivo tipo chullpa. Así, los sitios con mayor representación de mineral de cobre molido son Zapar, Peine, y Quitor, mientras que este material es registrado en menores cantidades en Catarpe Este, Catarpe
Oeste, Vilama Norte, Vilama Sur, Guatin, Topaín y Paniri. En Solor su representación es intermedia, pero con la diferencia que en este lugar se encuentra la mayor cantidad de mineral de cobre elaborado en forma de cuentas de collar. Esta situación es coincidente con las escasas cantidades de molinos y restos vegetales antes mencionadas, aun cuando no haya una relación directa entre estos materiales, a la vez que se reafirma la idea de una diferente organización socio-productiva, o económico-productiva de Solor frente a los otros sitios.

Zapar, Peine, Quitor, Paniri, Catarpe Este y Oeste presentan con diferencias cuantitativas, estructuras de patrón constructivo tipo chullpa, y los dos primeros registran tumbas al interior de los recintos, lo que hace posible atribuirles una carga simbólica significativa. En el caso de Topaín, el mineral de cobre se encuentra disperso en el suelo en asociación a una estructura pequeña rectangular identificada como "caja", comunes en el Loa Medio y Superior. En los restantes sitios, si bien no se identificaron estas estructuras, la presencia de mineral de cobre puede estar indicando algún tipo de manifestación ceremonial similar.

Al respecto, cabe señalar que el mineral de cobre esparcido en los pisos a modo de material challado en eventos ceremoniales tiene una amplia dispersión en la región atacameña, registrándose abundantemente en sitios del Intermedio Tardío y Tardío, entre los que podemos mencionar, además de los aquí trabajados: Talikuna, Mulorojte, Vega Salada, Incahuasi y Cerro Verde en la localidad de Caspana (siendo Cerro Verde, Vega Salada e Incahuasi centros productores de cobre, al menos desde estos períodos) (Uribe y Carrasco 1999); en Turi, Lasana y Alto Loa (sitios SBa-103, SBa119 y SBa-41). En este sentido, fue bastante recurrente en la región atacameña la depositación de mineral de cobre en los sitios, producto de eventos ceremoniales.

Si bien no existe una asociación clara entre categorías de instrumentos y productos en particular, podemos señalar la importancia del conjunto artefactual de molienda como intermediario entre los productos (y el significante de los mismos) y los eventos en que éstos participan. Así, ya sea dentro de un ámbito exclusivamente doméstico o religioso, los instrumentos de molienda son fundamentales en el procesamiento de productos consumidos tanto cotidiana como ocasionalmente, y 
su uso se vincula a actividades tanto familiares como públicas.

\section{Síntesis y conclusiones}

Se ha visto que los artefactos de molienda más representados en los sitios corresponden, en general, a molinos en su parte inmóvil, y dentro de éstos a conanas. Les siguen en popularidad las manos de moler en sus funciones originales y como elementos retomados para la percusión bipolar. Aun cuando se ha registrado una amplia gama de instrumentos que poseen más de una funcionalidad, éstos resultan bastante escasos, lo que sugiere que la multifuncionalidad de los instrumentos correspondería a situaciones eventuales no conformando un patrón de conducta generalizado, sino esporádico y concentrado en los sitios de Zapar, Peine y Solor.

Las muestras resultan bastante disímiles en cuanto a cantidad, generando contextos particulares en que resulta difícil establecer relaciones culturales entre los sitios, insinuándose más bien correlaciones funcionales, en que distintas categorías de sitios presentarían conjuntos artefactuales más semejantes entre sí. De este modo, tal como en el caso de los sitios defensivos, que concentran poco y nada de material de molienda, los sitios de Zapar y Peine, con una fuerte carga simbólica atribuible por la mayor cantidad de sepulturas que albergan dentro de sus límites, son los asentamientos con mayor representación y variedad de instrumentos, ofreciendo además un amplio panorama de artefactos reutilizados y con más de una función aparente. Asimismo, al ser estos sitios exponentes de una fuerte vinculación con poblaciones altiplánicas es posible pensar en una actividad de molienda de chañar, algarrobo y mineral de cobre relacionada con un eventual tráfico de estos productos, ya procesados, hacia el altiplano.

Solor presenta una problemática particular, ya que si bien es posible agruparlo bajo esta lógica junto a Zapar y Peine, la alfarería y la arquitectura lo vincularían a desarrollos más tempranos, teniendo además connotaciones más locales que altiplánicas. No obstante, en Solor es donde destaca la presencia de manos de moler por sobre la de molinos, constituyéndose en el asentamiento de comportamiento más singular con relación a los otros.
Si bien no hay certeza de los elementos que eran molidos, lo más probable es que los vegetales y minerales ocuparan la mayor atención al respecto. En efecto, se ha notado cómo la presencia de chañar, algarrobo, maíz y mineral de cobre se hace recurrente, con distintos énfasis en los sitios. Estos elementos mantienen una importancia no sólo económica, sin también ritual, ocupando un lugar destacado en la vida de las poblaciones atacameñas. En este sentido, si tales productos resultaban fundamentales para éstas, entonces los materiales de molienda adquieren una significación cercana a tales vegetales y minerales, por ser los instrumentos destinados a su tratamiento y elaboración, constituyéndose en piezas claves para el desarrollo de actividades tanto de tipo cotidiano como ceremonial. Esta situación, como se ha podido ver no registra cambios dentro de un contexto cronológico, sino que más bien funcional. No obstante, es significativa la asociación entre arquitectura altiplánica y mineral de cobre molido, aun cuando éste se encuentra durante varios períodos y en otros ámbitos challado en sitios sin esta arquitectura (p.e., sitios de "muro y caja").

Bajo la misma óptica es posible señalar asociaciones entre restos vegetales en contextos mortuorios, y una fuerte presencia de instrumentos de molienda, como son los casos de Zapar y Peine. No obstante, tal como acontece en Solor con relación a la frecuencia de instrumentos, Quitor muestra una elevada proporción de restos vegetales; sin embargo, no presenta material de molienda, aunque sabemos que alguna vez los tuvo (Mostny 1949). Esto es posible de explicar en función de las características defensivas del sitio y a la alta probabilidad de almacenamiento que pudo haberse dado en algunos de sus recintos especialmente destinados para ello, ya que, como se ha señalado, este sitio se correlaciona mejor con Vilama Norte y Sur.

De esta forma, es posible advertir al menos en cuanto a la asociación con restos vegetales que en los sitios del Período Intermedio Tardío y Tardío, en San Pedro y el Loa existe un comportamiento funcional, distinguiéndose sitios productores con escaso grado de procesamiento de productos (Guatin, Topaín); sitios donde se almacena y se procesa a pequeña escala (Catarpe Oeste, Quitor, Vilama Norte, Vilama Sur y Paniri), y sitios donde principalmente se procesa y consume 
(Zapar, Peine y Solor). Esta situación también puede ser extendida a la molienda de minerales, habiendo sitios fundamentalmente productores, como Cerro Verde, Vega Salada e Incahuasi Inka, y sitios consumidores, como el Cementerio de Los Abuelos, Talikuna, Turi, y prácticamente todos aquellos del Salar de Atacama, en especial aquellos con arquitectura y cerámica altiplánica.

Agradecimientos Para la realización de este trabajo debo agradecer al equipo del Proyecto FONDECYT 1000148 liderado por Mauricio
Uribe, Leonor Adán y Carolina Agüero. A mis colegas que también participaron de esta investigación: Bárbara Cases, Claudia del Fierro, Indira Montt, Lorena Sanhueza, Danisa Catalán, Patricia Ayala, Ulises Cárdenas y Josefina González. A Patricio de Souza, por su colaboración en el fichaje de piezas de los sitios de Zapar y Catarpe Oeste; al estudiante de arqueología Charles Garceau, por su colaboración en el fichaje de instrumentos de los sitios de Paniri y Topaín, y finalmente, a Lautaro Núñez, por su disposición y comentarios relacionados con el tema.

\section{REFERENCIAS CITADAS}

ADAN, L., 2003 Ms. Arquitectura y sistemas de asentamiento de los períodos Intermedio Tardío y Tardío de San Pedro de Atacama. Informe Proyecto FONDECYT 1000148, Santiago.

ALDUNATE, C., 1993. Arqueología del Pukara de Turi. En Actas XII Congreso Nacional de Arqueología Chilena. Museo Regional de la Araucanía T II: 61-78, Temuco.

ALLIENDE, P., V. CASTRO y R. GAJARDO, 1993. Paniri: Un ejemplo de tecnología agrohidráulica. En Actas XII Congreso Nacional de Arqueología Chilena. Museo Regional de la Araucanía T II: 123-128, Temuco.

BERENGUER, J., A. DEZA, A. ROMAN y A. LLAGOSTERA, 1986. La secuencia de Miriam Tarragó para San Pedro de Atacama: Un test por termoluminiscencia. Revista Chilena de Antropología 5: 17-54.

CORNEJO, L., 1990. La molienda en el Pukara de Turi. Chungara 24/25: 125-144.

GONZALEZ, J., 2003. Restos de alimentos en sitios tardíos de San Pedro. Boletín de la Sociedad Chilena de Arqueología 35, en prensa.

LYNCH, T. y L. NUÑEZ, 1994. Nuevas evidencias inkas entre Kollahuasi y río Frío. Estudios Atacameños 11: 145-164.

MARTINEZ, J. L., 1998. Pueblos del chañar y el algarrobo: Los Atacamas en el siglo XVII. DIBAM, Santiago.

MOSTNY, G., 1949. Ciudades atacameñas. Boletín del Museo Nacional de Historia Natural T XXIV: 125-213.
POLLARD, G., 1970. The cultural ecology of ceramic-stage settlement in the Atacama Desert. Submitted in partial fulfillment of the degree of Doctor of Philosophy, in the Faculty of Political Science, Columbia University, Columbia.

SANHUEZA, L. y M. URIBE, 2002 Ms. Análisis cerámico de los sitios habitacionales tardíos de San Pedro de Atacama. Informe de avance Proyecto FONDECYT 1000148, Santiago.

SERRACINO, G. y R. STEHBERG, 1974. Investigaciones arqueológicas en Guatin, San Pedro de Atacama. Estudios Atacameños 2: 7-57.

TARRAGO, M., 1989. Contribución al conocimiento arqueológico de las poblaciones de los oasis de San Pedro de Atacama en relación con los otros pueblos puneños, en especial el sector septentrional del valle de Calchaquí. Tesis Doctoral, Universidad Nacional de Rosario, Rosario.

URIBE, M., 2002. Sobre alfarería, cementerios, fases y procesos durante la prehistoria tardía del Desierto de Atacama (800-1600 DC). Estudios Atacameños 22: 7-31.

URIBE, M. y C. CARRASCO, 1999. Tiestos y piedras talladas: La producción cerámica y lítica en el Período Tardío del Loa Superior. Estudios Atacameños 18: 55-72.

URIBE, M., L. ADAN y C. AGUERO, 2003. Los períodos Intermedio Tardío y Tardío de San Pedro de Atacama y su relación con la cuenca del Loa. En Actas del XV Congreso Nacional de Arqueología Chilena, en prensa. 